http://dx.doi.org/10.12795/PH.1990.v05.i01.12

\title{
Fórmulas de tratamiento americanas y andaluzas en el S. XVI
}

Eva $M^{a}$ Bravo García

1. En el entorno social del siglo XVI se va a producir un intento de ascensión en la dignidad y consideración por parte de los individuos de los estamentos inferiores, que se va a reflejar en el lenguaje. Las formas de interlocución y las cortesías, adscritas a unas determinadas relaciones de superioridad e inferioridad, van a modificarse según los cambios sociales.

La documentación literaria y administrativa de la época muestra una preocupación constante por precisar el uso de estos términos y los autores asisten, desde un punto de vista crítico y receptivo, a los procesos de expansión y de rechazo que experimentarán algunas de estas expresiones.

1.1. ¿Qué se entiende por fórmula de tratamiento? El $D R A E^{1}$ registra entre sus acepciones:

(2)«Título de cortesía que se da o con que se habla a una persona; como merced, señoría, excelencia, etc.»

(3)«Vocativo de uso habitual en el coloquio, y referente a categoría social, edad, sexo, cualidades físicas o morales del interlocutor, con diversos matices de respeto o afecto: ¡Señor!, „Caballero!, ¡Señora!, ¡Niño!, ¡Chico!, „Hombre!, ¡Mujer!»

\footnotetext{
${ }^{1}$ Real Academia Española, Diccionario de la Lengua Española, 20" ed. (Madrid: Espasa-Calpe, 1984), S.v. tratamiento.
} 
La Real Academia distingue, además, el tratamiento impersonal: «Aquel que se da al sujeto de tercera persona, eludiendo el de merced, señoría, etc.»².

Ambas acepciones, junto con la consideración de las formas pronominales que no contempla la Academia, quedan englobadas en la definición que propone José $\mathbf{M}^{\mathrm{a}}$ Enguita: «se entiende por fórmula de tratamiento el empleo de un pronombre -o sintagma nominal- por medio del cual un hablante se dirige a su interlocutor ${ }^{3}$.

Estas fórmulas están directamente relacionadas con las personas gramaticales y pueden, desde un punto de vista sintáctico, realizar las funciones de sujeto, vocativo o complemento; conllevan todo un sistema de pronombres y adjetivos ${ }^{4}$, así como una selección en el paradigma verbal, que estará condicionada por la fórmula escogida. Dicha elección está, a su vez, vinculada a elementos ajenos a lo puramente linguiístico, relacionados con la estructura de la sociedad y con factores culturales.

1.2. En lo referente al sistema pronominal, hay que considerar que si nuestra lengua sólo contara con una forma para la indicación de cada una de las personas que participan en el proceso comunicativo, distinguiendo singular y plural, no cabría hablar de «tratamiento», pero desde el momento en que el oyente puede ser tú o usted, por ejemplo, la lengua está proporcionando una elección.

Esta duplicidad aparece por primera vez en los últimos tiempos de la latinidad: hacia el s. III d.C. surge la forma vos (originariamente $2^{\underline{a}}$ pers. pl.) para la $2^{\underline{a}}$ pers. sing., con el valor especial de un «tú de respeto», forma que pasó a las lenguas romances. Mucho se ha especulado sobre la causa de la aparición de este elemento, al que se le han dado incluso explicaciones de carácter psicológico o sociológico ${ }^{5}$ : lo cierto es que la forma de plural se asoció a la idea de majestad y de respeto; en definitiva, a la noción de una persona perteneciente a un orden social superior.

1.3. La sociolingüística ha tratado de abordar precisamente las interrelaciones que existen entre el lenguaje y la sociedad ${ }^{6} \mathrm{y}$, aunque mucho ha sido estudiado ya, quedan aún importantes cosas por hacer en aspectos como éste de las formas de interlocución. Estos estudios han venido demostrando, en síntesis, que el cambio de las condiciones sociales no sólo afecta al desarrollo diacrónico de una lengua o a la división geográficodialectal de la misma, sino a los propios contenidos lingüísticos, que cambian en buena

2 Por su parte, en el primer trabajo lexicográfico de la Academia, el Diccionario de Autoridades de 1732 (Madrid: Gredos, 1963), define así la voz tratamiento en una de sus acepciones: «Significa también el título de cortesía que se da a alguno: como merced, señoría, excelencia, etc.» (citado Aut.).

3 «Fórmulas de tratamiento en El Criticón», Actas de la I Reunión de Filólogos aragoneses (Zaragoza: Institución Femando el Católico, 1986), pág. 295.

${ }^{4}$ Cfr. Real Academia Española, Esbozo de una Nueva Gramática de la Lengua Española (Madrid: Espasa-Calpe, 1983), pág. 338 y sigs.

5 Para una síntesis de dichas teorías, cfr. C. Weinerman, Sociolingüística de la forma pronominal (México: Trillas, 1976), pág. 34 y sigs.

${ }^{6}$ Cfr. B. Schlieben-Lange, Iniciación a la sociolingüística (Madrid: Gredos, 1977), pág. 14. 
parte obligados por la evolución de la sociedad y la modificación de las circunstancias históricas y políticas?.

En toda época hay una serie de factores que son importantes; aquélla cuya estructura se conforme según un marcado sistema de jerarquías, dejará traslucir su rígida composición en la lengua, formando un diferenciado conjunto de pronombres de cortesía, como ocurrió en el mundo medieval.

2. En el siglo XVI las fórmulas de tratamiento no van a perder interés; muy al contrario, los autores reflejarán en las obras sus sentimientos y opiniones acerca de este particular, con alusiones directas que, dada la importancia que adquirió el tema llegan incluso a la burla, como en el caso de Lope de $\mathrm{Rueda}^{8}$, que pone en boca de un licenciado el siguiente párrafo:

«Porque yo, para convidalle, ni tengo blanca ni bocado de pan, ni cosa, ofrézcola a Dios, que de comer sea, y por tanto querría suplicar a vuesa merced que vuesa merced me hiciera merced de me hacer merced, pues estas mercedes se juntan con esotras mercedes que vuesa merced me suele hacer, me hiciere merced de prestarme dos reales» (El Deleitoso, IV, pág. 535).

La lengua del XVI había heredado las fórmulas medievales, pero prácticamente todas van a tener una importante transformación en esta centuria, que va a afectar tanto al carácter fono-sintáctico, como a los valores semánticos, como consecuencia de su práctica en una sociedad que, a lo largo de toda su variedad diastrática, va a pretender ser objeto de dichas cortesías. Aplicar a alguien una de estas fórmulas le hace adquirir consideración a los ojos de los demás, como afirma explícitamente el simple Melchior en una comedia de Lope de Rueda:

Melchior: «Pues aquese Melchior apúntele con alguna cosita al prencipio, porque no vaya a secas, y verá lo que pasa.

Leonardo: ¡Ah, ¿señor Melchior Ortiz?

M.: Agora soy contento. ¿Qué manda vuesa merced?

L.: ¡Oh, mal os haga Dios, que tantos términos habemos de tener para que salgáis!

M.: Que no lo hago en mi álima, sino porque sienta esta mala vieja que soy honrado en boca de vuesa merced; que para mi contento con un «ioyes?» me sobra tanto como la mar» (Eufemia, pág. 49).

2.1. Para la primera persona, a parte del pronombre yo, las altas jerarquías en el orden espiritual y temporal utilizaron Nos, que será aún general en el XVI en pragmáticas, cédulas y demás documenos administrativos expedidos por el Rey. Se utilizaba con verbo en $1^{\frac{a}{a}}$ pers. sing. o en $1^{a}$ pers. pl., siendo el primer caso el más frecuente

${ }^{7}$ Casos históricos concretos en los que se muestra claramente esta dependencia aparecen recogidos en C. Weinerman, op.cit., págs. 36-37.

${ }^{8}$ Teatro Completo, $2^{\mathrm{a}}$ ed. (Barcelona: Bruguera, 1976). 
excepto, claro está, cuando eran dos las personas reales, como ocurre en los privilegios concedidos por los Reyes Católicos al almirante Cristóbal Colón?:

«...ca Nos, por esta nuestra carta, desde agora para entonces vos fasemos (sic) merced de los dichos oficios de almirantadgo e visorey e governador...» Firmado: «Yo el Rey», «Yo la Reina» (págs. 156 y 157).

Este Nos aparece en la obra del cordobés Francisco Delicado ${ }^{10}$ en boca de un arzobispo, cuando requiere a la protagonista:

«De buena gana; tomá y venirnos a ver». (Lozana, pág. 314).

Como una imitación picaresca del uso por parte de la persona real, aparecerá en las «Ordenanzas Mendicativas» que aprende Guzmán de Alfarache ${ }^{11}$ :

«... y sea tenida por profesa, haya y goce las libertades y exempciones por Nos concedidas, con que de allí adelante no pueda dejar ni deje nuestro servicio y obediencia, guardando nuestras Ordenanzas y so las penas dellas» (pág. 383) ${ }^{12}$.

2.1.1. Por otra parte, podía utilizarse la $1^{a}$ pers. del plural, que suele conllevar una intención estilística o expresiva y da lugar a distintos tipos:

- plural de modestia;

- implicación del interlocutor o interlocutores en la acción, utilizando el llamado plural sociativo: cuando el clérigo cuenta a Guzmán y al arriero la historia de Ozmín y Daraja dice «volvamos a decir de Daraja los tormentos que padecía...» (Guzmán, pág. 219), pero es el único que narra; también Fernando de Herrera inicia así su composición «Por la victoria de Lepanto» ${ }^{13}$ :

«Cantemos al Señor, que en la llanura

venció del ancho mar al Trace fiero;» (pág. 56)

- referencias sociativas con cierto valor indefinido:

«No sé qué puede ser -dice Guzmán-, que deseando ser buenos nunca lo somos, y aunque por horas lo proponemos, en años nunca lo cumplimos ni en toda la vida salimos con ello. Y es porque no queremos ni nos acordamos de más de lo presente». (Guzmán, pág. 320).

${ }^{9}$ Hernando Colón, Historia del Almirante (Madrid: Historia 16, 1984).

${ }^{10}$ La Lozana Andaluza, ed. C. Allaigre (Madrid: Cátedra, 1985).

${ }^{11}$ Mateo Alemán, Guzmán de Alfarache, I, ed. B. Brancaforte (Madrid: Cátedra, 1984).

12 En el mismo texto se utiliza la fórmula «pena de nuestra merced» (pág. 380) que, según registra Autoridades es la «conminación que los Reyes usan, para amenazar con su indignación o castigo al que contraviniere a sus decretos o provisiones» (s. v. merced).

${ }^{13}$ Lyra Hispana (Madrid: Razón y Fé, 1958). 
- connotaciones humorísticas hacia la $2^{\mathrm{a}}$ persona:

«iHola, ce! ¿Habémonos de oir?» («ime habéis de oir?», dice un amo a su criado, $E l$ Deleitoso, V, pág. 542).

2.1.2. Finalmente, la $3^{\mathrm{a}}$ pers. sing. aparecía:

- en expresiones de carácter impersonal, uno, servidor, hombre, etc., de las cuales la última fue la más utilizada en el s. XVI:

Melchior: «Pardiez, aunque hombre hubiese de aprender para hacer cartas de mareaje, no le hiciesen atravesar más veces este camino; pero vaya».

M.: «Fíase el hombre en él pensando luego daremos la vuelta, y ha más siete horas que anda hombre como perro rastrero, y a mal ni a bien no le ha podido dar alcance». (Eufemia, págs. 111 y 77).

Escudero: «¿Qué buscáis, señora Lozana? ¿Hay en qué pueda el hombre servir a vuesa merced?» (Lozana, pág. 335).

«Pero saldrá el hombre desta cadena -dice un galeote refiriéndose a sí mismo-y todos nos entenderemos, y no digo más». (Pág. 56) ${ }^{14}$.

- cuando alguien habla de sí mismo utilizando su nombre propio o una construcción perifrástica:

Melchior: «Pues ni más ni menos andaba el sin ventura dè Melchior Ortiz Carrasco, hasta que fortuna me deparó a una parte una puertecilla por do vi salir algunas gentes...» (Eufemia, pág. 79).

2.2. En la referencia a la segunda persona de singular, es donde la lengua ofrece mayor variedad:

2.2.1. Rafael Lapesa ${ }^{15}$ señala que en la época del Mio Cid, vos («tú de respeto») es el tratamiento general entre nobles, e incluso entre cónyuges, y que su penetración en ambientes burgueses se va a observar ya en el Libro de Buen Amor.

Vos era la forma utilizada entre personas de igual condición y elevado nivel social, o por individuos de nivel inferior para dirigirse a alguien superior.

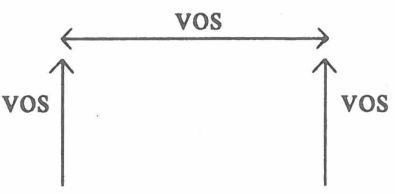

${ }^{14}$ Cristóbal de Chaves, Relación de la Cárcel de Sevilla (Madrid: El Arbol, 1983).

15 «Personas gramaticales y tratamientos en español», Revista de la Universidad de Madrid, XIX (1970), pág. 144 y sigs. 
De otra parte, el tuteo es general en buena parte de la documentación notarial de la época entre gente llana y, por supuesto, es el tratamiento que usa el superior para dirigirse al inferior.

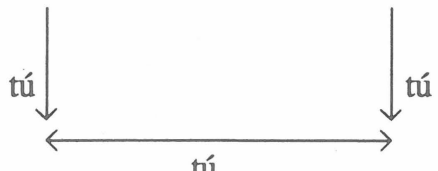

tú

Pronto van a aparecer alteraciones en este sistema: ya el Arcipreste de Talavera utiliza tú entre iguales de condición superior, forma que se extenderá a los géneros pastoriles; la literatura cortés alterna túlvos, circunstancia ésta que se observa también en las composiciones amorosas de la centuria que nos ocupa: Fernando de Herrera, por ejemplo, utiliza tú cuando habla la amada al amado, mientras que éste le responde con vos:

«Mil veces, por no ser ingrata, pruebo

vencer $t u$ amor, pero al fin no puedo /...

Señora, bien sabéis que mi cuidado todo s'ocupa en vos; que yo no siento...» (Elegía III).

Se produce, así, una pérdida de diferencia entre tú y vos, que va a ser definitiva cuando este último aparezca entre iguales inferiores, de lo que hay frecuentísimos ejemplos tanto en La Lozana como en Guzmán, así como en los personajes creados por Lope de Rueda: entre dos lacayos y un paje el tratamiento es vos, pero cuando riñen pasan a un tú ofensivo, acompañado en ocasiones de un adjetivo degradante:

Vallejo: «¿Quién es ladrón, babosillo?

Grimaldo: Tú lo eres, ¿hablo yo con otro?

V.: ¿Tal he de sufrir, que se ponga este desbarbadillo conmigo a tú por tú?» (Eufemia, pág. 67).

La conciencia de recibir un tratamiento de desprecio se plasma en la expresión $a$ tú por tú, que Autoridades define como «modo adverbial que vale descompuestamente, sin modo ni respeto. Dícese de los que riñen, diciéndose palabras injuriosas, y perdiéndose la cortesía» (s.v. tú).

La situación queda, pues, como muestra el siguiente gráfico:

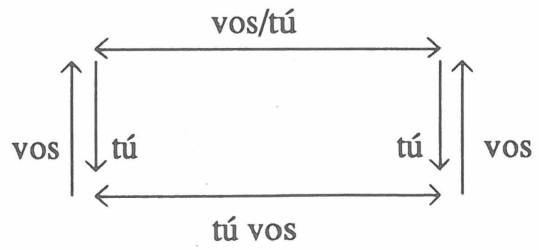


El abuso de esta fórmula por la extensión social que va adquiriendo, será el principal responsable de la pérdida de todo matiz de respeto en vos, justificando y haciendo urgente la aparición de nuevos tratamientos.

No hay que entender, sin embargo, que con esta expansión de vos desapareciera el tuteo. Lo que sí ocurrió fue que conforme vos alcanzaba ese nivel de familiaridad, fue desprestigiándose y abandonando todo valor afectivo, que volvió a recaer, casi exclusivamente, en tú. Jerónimo de Texeda escribía en 1619: «no usa el español la palabra tú sino con una mujer que quiere, o sus hijos, o otros niños, o con un criado de poca estima, o con algún pícaro» ${ }^{16}$. Y en el mismo año define Juan de Luna: «el primero [título] y más bajo es tú, que se da a los niños o a las personas que queremos mostrar grande familiaridad o amors ${ }^{17}$.

La confusión entre vos y tú originó una serie de alteraciones e intercambios entre los pronombres y las personas verbales que cada una conlleva. El desgaste de la noción de «respeto» en vos hizo que éste tomara en ocasiones los pronombres y formas verbales de singular, dando lugar a una mezcla que, si bien en la Península fue pasajera por la definitiva desaparición del tratamiento con $v o s$, en buena parte del territorio americano ${ }^{18}$ permanece hasta hoy constituyendo el fenómeno llamado voseo. «La palabra voseo comenta Ch. Kany- significa el uso de vos familiar singular en sustitución del tú, con formas verbales oscilantes entre la segunda persona del singular y la arcaica segunda persona del plural, junto con los pronombres $t e$, vos (por $t i$ ), y los adjetivos posesivos tu y $t$ tuyo ${ }^{19} \gg$.

En las obras de Lope de Rueda, se encuentra esta confusión en el habla de las criadas negras, junto a muchos otros rasgos característicos del habla de negros ${ }^{20}$ :

Eulalla: «Paréscete vos que no sa bon exemplos a la ventana de un dueña honradas recogidas coma yo, facer aqueya cortesía a taloras?» (Eufemia, pág. 113).

E.: «Ya lo veo, siñor; mas quiere vos sacarme na pues perdida na tierra que te conozco». (Id., pág. 116).

${ }^{16}$ Gramática de la lengua española (México: UNAM, 1979), pág. 62.

${ }^{17}$ Testimonio tomado de Ch. Kany, Sintaxis hispanoamericana (Madrid: Gredos, 1976), pág. 84.

${ }^{18}$ Para la extensión que actualmente tiene este fenómeno, cfr. íbid., pág. 80.

${ }^{19}$ Ibid., pág. 79.

${ }^{20}$ En los diálogos de Eulalla y Fulgencia, se pueden observar rasgos tales como la pérdida de consonantes finales, sobre todo de /s/ (fablamo y servimo, lo pajesicos), alternancias de $/ \mathrm{r} / \mathrm{y} / 1 / \mathrm{con} / \mathrm{d} /$ (turo «todo», criaror), confusiones entre los fonemas sibilantes, dando lugar a soluciones seseosas (sinco, pajesicos) o ceceosas (cerradaz y recogidaz), yeísmo (yama «llama», cabayo, aqueya), lusismos fonéticos y morfológicos (na cielos è na tierras), etc.

Cfr. al respecto E. de Chasca, «The Phonology of the Speech of the Negroes in the Early Spanish Drama», Hispanic Review, XIV (1946), págs. 322-339; F. Weber de Kurlat, «El tipo cómico del negro en el teatro prelopesco. Fonética», Filología, VIII (1962), págs. 325-401. Para una justa valoración de esta habla respecto a las caracterizaciones lingüísticas de otros «graciosos» del teatro áureo, cfr. J. A. Frago Gracia, «Tópicos lingüísticos y tipos cómicos en el teatro y en la lírica de los siglos XVI-XVII», Philologia Hispalensis, I/1 (1986), págs. 85-116. 
Fulgencia: « $¡ \mathrm{Ah}$, siñor! Pléguete a vos que ante que la terra le eche sobre la ojo, me vea yo casados con mi queridos». (Tymbria, pág. 454).

Esta confusión afecta también a la forma vuestra merced:

F.: «Sí, por cierto, siñor; fablamo y servimo a buena fe, ya ve, como la persona samo tan negro cerradaz y recogidaz, aunque samo na campos, no te maraviya vosa mercé, y como tampoco sa forana esa cayando, que no lo asamo decir óxete ni moxte». (Id., pág. 448).

E, incluso, en el habla del lacayo Vallejo, se observa con el pronombre él, referido a una $2^{a}$ pers. sing.:

Valiano: «Todo me paresce bien si no te emborrachases tan a menudo.

Vallejo: $E l$ es mi señor y tengo de sufrirte; mas a decírmelo otro, no fuera mucho que estuviese con los setenta y dos». (Eufemia, pág. 87).

2.2.2. En textos literarios andaluces y americanos del XVI se encuentra tú en los siguientes casos:

$\left.1^{2}\right)$ Es el tratamiento habitual entre personas de baja condición social y hacia inferiores: en los pasos de Lope de Rueda aparece entre ladrones, entre el paje y el bobo, etc. ${ }^{21}$; M. Alemán lo pone en boca de cuadrilleros (pág. 194) y es el que generalmente recibe el pícaro Guzmán²; en La Lozana es común entre comadres, vecinas, así como entre la Lozana y las mujeres de su misma condición ${ }^{23}$.

Si entre iguales que se tutean se utiliza en un determinado momento vos, éste irá cargado con toda certeza de un fuerte contenido irónico o jocoso que puede venir reforzado con la mención del nombre propio del interlocutor, precedido de algún otro tratamiento:

Cristina: «Haría mejor a buena fe, señor Melchior Ortiz, de mirar por aquel cuartago». (Eufemia, pág. 58).

Con una finalidad semejante se observa el uso de la $3^{\mathrm{a}}$ persona; así, cuando Melchior se burla de la vieja Ximena, utilizará invariablemente la señora:

Melchior: «¿Cómo quiere la señora que no se peguen a ella los moxquitos, si de ocho días que tiene la semana se echa los nueve hecha cuba?

Ximena: [...] ¡Ay! Plegue a Dios que en agraz te vayas.

${ }^{21}$ El Deleitoso, V, págs. 540 y sigs.

${ }^{22}$ Así le hablan el fraile (pág. 257), el huésped (pág. 258), su ama la mujer del cocinero (pág. 293), el mendigo viejo (pág. 386), etc.

${ }^{23}$ Lozana tuteará, además al estufero (pág. 225), a la esclava negra (pág. 284), a la criada Magdalena (pág. 300), etc. 
M.: ¿En agraz? A lo menos no le podrán comprender a la señora esas maldiciones, aunque me perdone.

$\mathrm{X} .:$ ¿Por qué, molde de bodoques?

M.: ¿Cómo se puede la señora chupa de palmito ir en agraz, si a la contina etá hecha uva?

X.: ¡A osadas, don mostrenco, si no me lo pagárades!

M.: Pase adelante la cara de mula, que tiene torozón». (Eufemia, págs. 56-57).

$\left.2^{2}\right)$ Lo usan personas entre las que hay un lazo familiar o amoroso:

- de tú se hablan la madre de Guzmán y su protector: «Por tus ojos, niña, que me pesa de habello hecho» (pág. 129); así como los amantes Clorinda y Dorido (Guzmán, pág. 470 y sigs.);

- entre los hermanos Eufemia y Leonardo:

E.: «QQué ¿Todavía estás determinado de caminar sin saber a dó? /.../ Mi hermano eres, pero no te entiendo...»

L.: «Cara y amada Eufemia, no procures de estorbar con tus piadosas lágrimas lo que tantos días ha que tengo determinado». (Eufemia, págs. 53 y 54).

Una muestra de que el tuteo era la forma preferida entre amantes se encuentra en la escena final de esta obra, cuando la protagonista tutea a su supuesto amante en tanto que éste niega tal relación y le contesta con vos:

E.: «iAy, traidor! ¿Qué tú no has dormido conmigo?

Paulo: Que digo que no os conozco ni sé quién sois». (Id., pág. 126).

La pareja Lozana-Rampín, sin embargo, emplea en sus primeras relaciones vos, pero conforme avanza la narración se impone el tuteo; no es éste un caso de adquisición de confianza entre los amantes, más bien se corresponde de forma paralela con el proceso de degradación que sufre el personaje de Rampín hasta convertirse en un simple criado. La Lozana empieza ya a hablarle de tú en el mamotreto XIX, delante del Valijero, mientras que a solas acababa de utilizar vos:

L.: «Pues hacé vos ansí siempre, que hinchiremos la casa a tuerto y a derecho. Eso me place, que sois hombre de la vida y no venís vacío a casa [...].

R.: No curéis, que a todo me hallaréis, salvo a poco pan.

L.: Vuestra merced sea bienvenido, como agua por mayo» [...] [a Rampín] -Daca el aguapiés. Muda aquellas sábanas. Toma esa cabellera. Dale el escofia. Descalza a su merced. Sírvelo, que lo merece, porque te dé la bienandada». (Pág. 268-269).

Y más adelante, cuando todos lo consideran como un simple criado ( Decí vuestra ama,no os avergoncéis», pág. 339), el tuteo será general en público y en privado; el uso de vos sólo será señal de enojo:

L.: «¿Qué queréis? ¿Por dineros venís? ¡Pues tan blanco el ojo! ¿No’s di ayer tres julios? ¿Ya los gastastes? ¿So yo vuestra puta? ¡Andá, tornaos a casa!» (pág. 340). 
$3^{\circ}$ ) Entre iguales de condición superior:

- Fernando de Alva lo pone en boca de embajadores: «¿A qué vienes aquí? ¿Qué embajada es la que traes? Quiero saber de ello y ¿sabes a quién se la traes?» (pág. 240)24.

- Las Casas lo utiliza entre soldados: «Préstame un cuarto de un bellaco desos para dar de comer a mis perros...» (pág. 136).

$\left.4^{\circ}\right)$ De superior a inferior, excepto en el caso del Rey, que se dirige a sus súbditos con un vos arcaizante:

«...e queriendos honrar e faser merced por lo susodicho, es nuestra merced e voluntad que vos el dicho Christóbal Colón...» (Historia del Almirante, pág. 155) ${ }^{25}$.

«Por cuanto por parte de vos, el gobernador Alvar Núñez Cabeza de Vaca, vecino de la ciudad de Sevilla, nos hicísteis relación diciendo que vos habíades compuesto un libro...» (pág. 146) ${ }^{26}$.

Asimismo, se produce un cambio en el tuteo a un inferior considerado cuando hay enfado (cfr.2.2.2.2 ${ }^{\circ}$ ) o cuando se rompe la confianza entre ambos; así, Eufemia tutea normalmente a su criado, pero cuando éste colma su paciencia dice: «Pues si lo sabéis, haceldo y despachá, que vuestro señor es ido a oir misa...» (pág. 55).

Y cuando Valiano descubre la traición de su viejo criado Paulo, el tuteo que ambos utilizaban cambiará con un tono seco y amenazador: «Poné la mano en vuestra espada, Paulo» (Eufemia, pág. 126).

$\left.5^{\circ}\right)$ Tú es, asimismo, la forma con la que se dirige el autor al lector, tanto en Guzmán como en $L a L_{o z a n a^{27}}$, o con la que personajes gentiles hablarán a reyes o personas de alta dignidad; de esta manera, siguiendo el gusto clásico, Dajara e Isabel la Católica se tutean:

«Ya entenderás, Daraja, lo que deseo tus cosas y gusto. En parte de pago dello te quiero pedir una cosa en mi servicio [...]. Daraja le respondió: Haré con entera voluntad lo que tu Alteza me manda. Porque habiendo obedecido, si hay algo en mí de alguna consideración, de hoy más estimaré por buena, y lo será sin duda, que me lo darán tus atavíos y suplirán mis faltas» (Guzmán, pág. 199).

Un indio tutea al gobernador en la crónica de Ruy Díaz de Guzmánn ${ }^{28}$ : «...vengo enviado de tu hermano el capitán Ruy Díaz [...] a decirle que le socorras con gente española [...], y para poder llegar a $t u$ presencia, me ha sido preciso venir con disimulo por entre estos pueblos rebeldes» (pág. 240).

${ }^{24}$ Femando de Alva Ixtlilxochitl, Historia de la nación chichimeca (Madrid: Historia 16, 1985).

${ }^{25}$ Brevisima relación de la destrucción de las Indias (Madrid: Sarpe, 1985).

${ }^{26}$ Alvar Núñez Cabeza de Vaca, Naufragios y comentarios (Madrid: Historia 16, 1984).

${ }^{27}$ Lope de Rueda, sin embargo, en el «introito» que hace a algunas de sus piezas no sólo trata a su público de «vuestra merced», sino que les dedica las más elevadas cortesías para captar su benevolencia: «generoso auditorio» (Los Engañados, pág. 194), «nobles auditores» (Medora, pág. 280), «ilustres y agradecidos señores» (Camila, pág. 358), «muy magníficos señores» (Tymbria, pág. 422).

${ }^{28}$ La Argentina (Madrid: Historia 16, 1986). 
$\left.6^{\circ}\right)$ Las exortaciones a entes irreales, ciudades o patrias, y las exclamaciones en general $^{29}$ :

«iOh, epicúreo, desbaratado, pródigo, que locamente dices comer tantos millares de ducados de renta...! (Guzmán, pág. 252).

«iAh, ah España! ¡Amada patria, custodia verdadera de la fe! ¡Téngate Dios de su mano...!» (Id., pág. 401).

- Herrera impreca al río Betis:

«Sosiega el curso, tú, profundo río, oye mi gloria, pues también oíste mis quexas en tu puro assiento frío» (Elegía III)

$7^{\circ}$ ) Y, finalmente, aunque en ocasiones aparezca vos, es la forma general en los refranes y expresiones sentenciosas muy abundantes en La Lozana, de acuerdo con el gusto renacentista:

«por do fueres, de los tuyos halles» (pág. 206);

«...que, como dice el judío, no me veas mal pasar, que no me verás pelear» (pág. 249); «iA tu tía, esa zampoña!» (pág. 279);

«Ve do vas, y como vieres, ansí haz, y como sonaren, así bailarás» (pág. 283);

«... pues año de veinte e siete, deja a Roma y vete» (pág 299).

2.2.3. Por las mismas fechas que vos, sufre un similar proceso de desprestigio la forma don: «Título honorífico que se daba en España antiguamente a los caballeros y constituidos en dignidad» (Aut., s.v.).

En la primera mitad del XVI, señala Marichalar ${ }^{30}$, no lo usaban los capitanes, cortesanos y secretarios de Carlos I, situación que señala Covarrubias ${ }^{31}$ : «Muchas casas de señores han rehusado el don, y no se le ponen; y por estos pocos que le dexan le han tomado muchos, que no se les deve. En las mujeres se admite con más indulgencia y facilidad».

En efecto, estaba extendido en las mujeres tanto en los textos literarios como en los jurídicos, en consonancia con el afán de medro social de la época:

«El [nombre] propio era Marcela, su don por encima despolvoreado, porque se compadecía menos dama sin don, que casa sin aposento, molino sin rueda ni cuerpo sin sombra». (Guzmán, pág. 140).

En contraste con esto, Gila, la protagonista de La serrana de la Vera, obra del ecijano Luis Vélez de Guevara, rechaza como mujer rústica y respetuosa de las pág. 40.

${ }^{29}$ Cfr. C. Bobes, Las personas gramaticales (Santiago de Compostela: Universidad de Santiago, 1971),

30 «El uso del don en Garcilaso», RFE, XXXV (1951), pág. 128. 
diferentes condiciones sociales, su casamiento con el capitán y todo lo que ello conlleva:

«El señor capitán busque en Plasencia

mujer de su nobleza que le iguale,

que yo soy una triste labradora

muy diferente dél, para los campos

buena que me conocen, y no quiero meterme agora a caballera [...]

aprendiendo de nuevo reverenzias, que será para mí darme ponzoña,

y Gila no es buen nombre para doña». (pág. 137).

El Inca Garcilaso mos ofrece en la segunda parte de sus Comentarios Reales ( $L a$ conquista del Perú $)^{32}$, una observación sobre la amplitud que tuvo este tratamiento en la sociedad americana:

«Francisco Pizarro, a quien de aquí en adelante llamaremos don Francisco Pizarro, porque en las provisiones de su majestad le añadieron el pronombre don, no tan usado entonces por los hombres nobles como ahora, que se ha hecho común a todos; tanto que los indios de mi tierra nobles y no nobles, entendiendo que los españoles se le ponen por calidad, se lo ponen también ellos y se salen con ello. A Diego de Almagro llamaremos ansimismo don Diego, porque fueron compañeros, y es razón que lo sean en todo, pues en nada fueron desiguales». (Pág. 34) ${ }^{33}$.

En efecto, lo van a usar, entre muchos otros ${ }^{34}$, don Antonio Cortés, indio que reclama en una carta de 1552 el reconocimiento de un escudo de armas ${ }^{35}$; don Martín Cortés, hijo del conquistador y de la Malinche ${ }^{36}$; don Juan de Zaldívar Cortés Moctezuma $^{37}$; y el propio don Fernando de Alva Ixtlilxochitl.

Hace bien el Inca Garcilaso en puntualizar que el don le fue otorgado a Pizarro en las provisiones reales -como a Cristóbal Colón ${ }^{38}$ - ya que no sucedía así en todos los casos. Contra esto se va a dirigir la pluma satírica de Rosas de Oquendo ${ }^{39}$ :

${ }^{31}$ Tesoro de la lengua castellana o española (Madrid: Tumer, 1977).

32 Obras Completas (Madrid: Atlas, 1960).

${ }^{33}$ El don lo van a utilizar los descendientes del conquistador. Así, dice su hija Francisca en una carta: «Yo y don Francisco mi hermano como leales vasallos de su M. [...] suplicamos a V. Alteza tenga en memoria los muchos y leales servicios quel marqués don Francisco Pizarro nuestro padre hizo...», y firma «doña Francisca Pizarro», Sevilla, 1551 (A.G.I., Indiferente General- 1561).

${ }^{34}$ Para otros casos, cfr. A. Rosenblat, «Nivel social y cultural de los conquistadores y pobladores del siglo XVI», en Los Conquistadores y su lengua (Caracas: Universidad Central de Venezuela, 1977), pág. 74 , ns. 36 y 37.

${ }^{35}$ A. G. I., México- 96.

${ }^{36}$ E. Bravo García, Transcripción y estudio lingüístico de la «Historia de los descubrimientos de Nueva España» de Baltasar de Obregón (Sevilla: Universidad de Sevilla, 1989), pág. 399.

${ }^{37}$ A. G. I., Guadalajara- 4.

38 «E vos podades dende en adelante llamar e yntitular Don Christóbal Colón, e asy vuestros fijos e subcesores en dicho oficio e cargo se puedan intitular e llamar don, e Almirante, e Viso-rey e Gobernador dellas...» H. Colón, op. cit., pág. 155. 
«QQue buena fuera la mar, amiga de gente grave, si lo que hace con los vinos hiciera con los linages! que avinagrando los ruines los buenos perficionara. Mas son contrarios efectos los que en estos casos hace, que a los bajos hace nobles, y a los nobles baxos hace, y en las playas de las Indias qué de bastardos que nacen! qué de Pedros Sánchez Dones! qué de Dones Pero Sánchez! [...]

Todos son hidalgos finos de conocidos solares; no viene acá Joan Muñoz, Diego Gil ni Luis Hernández, sino todos caballeros y personas principales. Sólo yo soy un pobrete sin Don y con mil azares...»

Un proceso semejante se observa en la Península, donde será Quevedo ${ }^{40}$ quien cuente la situación de la corte:

«Cuántas tú no conocieres, tanta hallarás doncellas: que los virgos y los dones son de una misma manera». («Instrucción y documentos para el noviciado en la corte», pág. 898)

«... el cabello como el don, para no decir postizo, negro e él, pues acompaña dentro en Sevilla a Calvino»; («Pintura de la mujer de un abogado, abogada ella del demonio», pág. 960)

«Era su nombre Juana, hija de un zurrador y una gitana. Subió a fregona, y se llamó Ana Pérez con ayuda de un sastre y de un alférez [...]

${ }^{39}$ Versos recogidos por Baltasar Dorantes de Carranza, Sumaria relación de las cosas de la Nueva España (México: Impr. del Museo Nacional, 1902), págs. 150-151.

40 Obras completas, I, Poesía original (Barcelona: Planeta, 1974). 
Caminó con aquesto viento en popa, pues sacó faldellines

y se subió a chapines, torció soplillo y trujo saya y ropa;

llamóse doña, en pago por concierto, después que la dio un conde perro muerto:

que los dones que tienen estas tales, como son por pecados, son mortales.

Llamóse doña Luisa, cosa que a ella misma le dio risa;

y a caza de apellidos, por no pagar el don de vacio un hora, a la corte se vino hecha señora, con joyas y vestidos; adonde, por lo puta y por lo moza, se llamó doña Julia de Mendoza». («A cierta dama cortesana», págs. 647-648)

«Doctor, Don tú te le pones, el Montalbán no le tienes, con que quitado uno y otro sólo te queda Juan Pérez». («Redondillas de don Francisco de Quevedo contra el doctor don Juan Pérez de Montalbán», pág. 1192)

La desvirtuación de este originario título, propició su aparición antepuesto a sustantivos o adjetivos, en expresiones de ofensa o enfado que conllevan la forma vos, aún en aquellos personajes que reciben tú, como en los siguientes ejemplos de Lope de Rueda:

«iA osadas, don mostrenco, si no me lo pagárades!» (Eufemia, pág. 57).

«iAh, don traidor, que agora pagaréis lo que al cuartaguillo hecistes estar ayuno! ¿Acordaisos?» (Id., pág. 80).

«¿Vos, Lucas, de qué huís? ¡Toma, toma, don rapaz! Tened en cuenta de venir presto del mandado». (El Deleitoso, I, 494).

«Toma una higa de pan para vos, don villano.

Pero tomad vos esto, don ladrón tacaño». (Id., pág. 565).

2.2.4. De los sustantivos abstractos que va a ocupar el uso de respeto, se encuentran testimonios esporádicos desde el siglo XIII, pero es en el XV y a todo lo largo del XVI cuando van a proliferar. Vuestra merced será el que se generalice, pero junto a él aparecerán otros de menor difusión, como vuestra majestad o vuestra alteza, reservados para reyes y príncipes, respectivamente. En las crónicas de la conquista aprece en boca de indios para dirigirse a sus señores naturales:

«... pues están con tanta aficción los mexicanos y tenochas, hasta ver en qué ha de venir a parar esta prisión y calamidad de vuestra alteza...» (Historia de la nación chichimeca, pág. 99). 
De vuestra excelencia ${ }^{41}$ trata Rampín al maestresala (Lozana, pág. 262), el Inca Garcilaso al Duque de Braganza (la Florida, pág. 61) y Díaz de Guzmán el Duque de Medina-Sidonia (La Argentina, pág. 51). Vuestra señoría lo reserva Guzmán para embajadores y cardenales (Guzmán, págs. 413, 416, 459 y pássim), mientras la Lozana lo prodiga al embajador, al obispo, al arzobispo (Lozana, págs. 167, 261, 267 y pássim). Otras formaciones como vuestra reverencia, vuestra magnificencia, vuestra ilustrísi$m a$, etc., tuvieron mayor concreción en cuanto a las personas a las que podían ser aplicadas.

Ocasionalmente, pueden ir con posesivos correspondientes a la $2^{\mathrm{a}}$ pers. de singular: tu señoría, tu merced, etc. (cfr.2.2.2.5); y con mayor frecuencia de $3^{\text {a }}$ pers. de singular: su merced, su majestad, para dirigirse al receptor, uso este último tachado de aldeano y rústico por G. Correas en $1.627^{42}$.

Lope de Rueda lo pone en boca del simple Alameda:

«Pues, ¿qué quiere agora, señor, su merced Diego Sánchez? [...] Fresco estaría allí su magnificencia» (El Deleitoso, II, 513-514).

En el Guzmán, lo emplea una casera del Aljarafe y un montañés:

«Y bien, ¿qué es lo que mandan los señores? ¿Quiéren algo sus mercedes?» (pág. 127).

«¡Mal hora!, señores, perdonen sus mercedes, que ¡ma Dios! no hay cosa que tanta sed y sueño poña como sinsaborías» (pág. 145).

En 1.613, registra también este uso la obra de Vélez de Guevara, en la que el capitán se dirige a la protagonista:

«Pues bien, ¿qué importa, señora Gila, cuando fuera su merced dos Hércules?» (La serrana..., pág. 84).

De todas ellas, su merced es la que tuvo mayor vitalidad, permaneciendo en Andalucía hasta el s. XIX (hay testimonios en Fernán Caballero y en Valera, entre otros), para indicar la relación de inferior a superior. Actualmente se conserva en México, El Salvador, Colombia, Venezuela, Ecuador y Chile ${ }^{43}$.

Vuestra merced tiene sus primeras documentaciones a principio del $\mathrm{s} . \mathrm{XV}$, según $\mathrm{J}$. Corominas ${ }^{44}$, y hacia 1.530 se usa ya entre iguales y con inferiores distinguidos. Esta

41 «Tratamiento, título y cortesía que se da al que es Grande de España, y que el día de hoy conforme a estilo se ha extendido a otras personas, según su grado» (Aut., s.v. excelencia).

${ }^{42}$ Arte Kastellana (Santiago de Compostela: Universidad de Santiago, 1984).

${ }^{43}$ Lapesa, art. cit., pág. 149.

${ }^{44}$ J. Corominas- J. A. Pascual, Diccionario crítico etimológico castellano e hispánico (Madrid: Gredos, 1980 y sigs.), s.v. vos. 
construcción sufrió diversas simplificaciones hasta llegar al actual usted ${ }^{45}$ : vuesa merced es general en las obras de Lope de Rueda y Mateo Alemán, mientras Delicado aún escribe en 1528 vuestra merced. De la forma con simplificación del grupo [str], se derivan vuesarced, vuesansted, vuesasté, etc., y otras «totalmente vulgares -afirma Lapesa- que durante el siglo XVII eran propias de valentones, criados y lacayos ${ }^{46}$.

Varias de estas últimas se pueden encontrar en la Relación de la Cárcel de Sevilla, obra que C. de Chaves debió escribir entre 1585 y 1597. En ella, vuesa merced sólo la utiliza una vez un procurador, mientras que los presos prefieren vuesa-erced, vuarced, voarcé, voecé o veecé:

«Pues yo no veo la herida. Si vuesa-erced la ve, ponga ahí que vido una herida en un hombre que no tiene la justicia que ver con él». (Pág. 19).

«Déjeme todo hombre, y vuarced tape eso ahí como con algo». (Pág. 19).

«Ese rosario que voarcé tiene es mío, démelo». (Pág. 19).

«Allá a los jodíos pinte voecé con calzas, y no a mí». (Pág. 39).

«Veecé lo hizo mal en alegar que era manco y quebrado, porque no le echaran a galeras». (Pág. 50).

Vuacé y voacé se encuentran en el diálogo entre el Cabo y el bravo Andrés de La serrana...:

Cabo: «Vuazé se tenga y ninguno

se mueva a sacar la espada [...]

Andrés: Basta que voazé lo diga». (Pág. 149).

Usted está documentado en la crónica de Díaz de Guzmán (1612), aunque J. Corominas, J. Pla y Alvar-Pottier la registren por primera vez en 1620:

«Desvíense ustedes un poco, que yo me doy por preso [...]. A usted, don Francisco entrego mis armas, y agora hagan de mí lo que quisieren». (Pág. 166) ${ }^{47}$.

2.2.5. Para completar el panorama, hay que recordar que a medidados del s. XVI surgió otra posibilidad para dirigirse con respeto al interlocutor: la forma éllella con verbo en $3^{\mathrm{a}}$ pers. sing., y con valor de respeto. «Los avaros de cortesía -dice Covarrubiashan hallado entre v.m. y vos este término él» (Tesoro, s.v.).

Lozana: «para vuestra merced no hay priesa, sino vagar y comoél mandare». (Lozana, pág. 308).

${ }^{45}$ Cfr. el cuadro que ofrecen M. Alvar- B. Pottier, Morfología histórica del español (Madrid: Gredos, 1983), pág. 133.

${ }^{46}$ Art. cit., pág. 147.

${ }^{47}$ No obstante, como suele ocurrir con el manejo de obras que no están reproducidas en edición facsimilar, es conveniente tomar con prudencia este dato, ya que aunque las ediciones se muestran coincidentes, bien podría tratarse de una simplificación por parte de los editores. De todas formas, el uso de usted debió adquirir una gran difusión ya en el último decenio del siglo XVI. 
De otra parte, se podía aludir con el nombre propio del interlocutor o con un sustantivo o adjetivo sustantivado, cargado en la mayoría de las ocasiones, de ironía y humor, con verbo en $3^{\mathrm{a}}$ pers. de sing.:

«Sea bien allegado el bueno de Alonso...» (El Deleitoso, III, pág. 517).

Ximena: «Pase adelante el de los buenos recados.

Melchior: Valla ella la de las buenas veces». (Eufemia, pág. 62).

«El bellaco Diego Mazorca, cómo sale gordo!» (Lozana, pág. 331).

«¿Y adónde va el bobito?» (la ventera en Guzmán, pág. 147).

«¿Y el señor mancebito?» (el arriero en íd., pág. 248).

«Bien ¿qué dices agora poca ropa? ¿A qué bueno por acá el caballero de Illescas? (el cocinero, íd., pág. 288).

2.2.6. Finalmente, en La Lozana aparece ya un temprano testimonio del uso de se con valor referencial de $2^{\mathrm{a}}$ pers.:

Mercader: «Señora, ¿qué se hace?» (pág. 181).

Escudero: «Dejemos esto ¿dónde se va que gocéis?» (pág. 336).

2.3. Para la designación de tercera persona, o persona ausente, las posibilidades eran:

$1^{\circ}$ ) Su más un sustantivo abstracto de respeto: su merced, su santidad, su ilustrísima, su majestad, etc.

$\left.2^{2}\right)$ O bien el nombre propio o apelativo, pudiendo ser este último genérico o designador de cargos, oficios, título, etc. Dicho nombre puede ir acompañado de artículo, demostrativos, adjetivos, etc., 0 , incluso, constituir una designación humorística:

«Dadle en qué envuelva el Conde de Carrión». (Lozana, pág. 333), dice Trinchante a Rampín después de que éste se haya caído en el pozo ciego.

3. Merece una atención especial -aunque deba ser breve por la finalidad que aquí nos ocupa- la documentación de carácter jurídico y administrativo. Lógicamente, los contenidos de este tipo de textos no pueden ser los mismos y se observa en ellos una fuerte tendencia tradicional. Una fecha fundamental para el estudio de estos valiosísimos testimonios es el 8 de Octubre de 1586-1587 para la documentación americana, año en que se hace pública la «Pragmática de los tratamientos y cortesías» dictada por Felipe II ${ }^{48}$.

Desde el s. XV, habían proliferado formas de cortesía que resultaban excesivas y embarazosas para la austeridad que el monarca quería dar al aparato burocrático del estado. Su reglamentación, pues, viene dada no por cuestiones diplomáticas o lingüísticas, sino más bien por razones de carácter sociolinguiístico:

${ }^{48}$ A. Heredia Herrera, «La pragmática de los Tratamientos y cortesías, fuente legal para el estudio de la Diplomática moderna», Estudios de diplomática indiana (Sevilla: Diputación Provincial, 1974), págs. 815. 
por «la desorden y abuso que había en el tratamiento de palabra y por escrito, por haber venido a ser tan grande el exceso y llegado a tal punto que se hayan ya visto algunos inconvenientes y cada día se podían esperar mayores, si no se atajase y reformase, reduciéndolo a algún buen orden y término antiguo, pues la verdadera honra no consiste en vanidades, de títulos dados por escrito y por palabras, sino en otras causas mayores, a que estos no añaden ni quitan». («Pragmática», pág. 10).

Así, las cartas tanto oficiales como privadas deberán ceñirse a un sencillo esquema: bajo la cruz, el título Señor para el rey o el que convenga según el destinatario, y en la despedida «Dios guarde a la católica persona de vuestra majestad», sin ninguna cortesía, y la firma. En las cartas particulares no se admitía siquiera título o tratamiento bajo la cruz, y en el remate sólo «Dios guarde a v.s.» o «a v.m.» 0 «Dios os guarde»; fecha (lugar y día) y firma ${ }^{49}$.

Los documentos anteriores a esta Pragmática presentan fórmulas mucho más recargadas: a Carlos I se le dedica «Su Majestad», «S.C.C.M.», «C.C.R.M.», «A la S.C.C.M. del invictísimo emperador don Carlos rey nuestro señor», etc. A Felipe II: «al muy alto y esclarecido príncipe nuestro señor», «muy alto y poderoso y serenísimo príncipe nuestro señor», «S.C.M.», «C.C.R.M.», etc., testimonios todos ellos tomados de la riquísima documentación conservada en el Archivo de Indias de Sevilla.

Las cortesías introducidas en medio de las cartas o al final (fórmulas de sometimiento y vasallaje), prohibidas totalmente en la Pragmática, eran las que aprovechaba el autor de la carta para deshacerse en elogios de la persona real. Muchas de ellas eran «clichés» heredados de la tradición notarial, pero cada cual procuraba darle un toque personal:

«De vuestra majestad humilde vasallo que sus reales pies besa» (México, 1554); «cuya real persona acreciente nuestro señor por largos años [...]. De V.S.C.C.M. menor criado» (doctor Hernán, Sevilla, 1551);

«guarde nuestro señor la muy alta y muy poderosa persona de V. alteza por largos tiempos con el aumento de más reinos como vuestra alteza y los leales vasallos de su majestad y de V. alteza desean /.../. Las manos y pies de V. alteza besa» (doña Francisca Pizarro, Sevilla, 1551);

«guarde y aumente nuestro señor el felicísimo estado de V. majestad por muchos años en su santo servicio, amén. De V.C.C.M. mínimo siervo y vasallo» (don Antonio Cortés, 1552).

4. La sociedad española de la primera centuria áurea era, como se ha visto por los testimonios aducidos, muy amante de los tratamientos. La naciente sociedad americana lo iba a ser aún más. Desde los primeros momentos de la conquista, se pone de manifesto el carácter ceremonioso de las relaciones entre los componentes de la hueste indiana ${ }^{50}$.

49 Ibid., págs. 12-13.

50 «El trato entre superiores e inferiores en el ejército español tenía, en general, un tono muy marcado de cortesía, confianza y sentido patriarcal», G. Friederici, El carácter del descubrimiento y de la conquista de Amércia (México: FCE, 1986), pág. 370. 
J. Durand, en su tradicional trabajo La transformación social del conquistador, pone de manifiesto cómo pese a que una gran mayoría de los que conformaron la nueva sociedad eran gentes de condición social alta o me dia (hidalgos, funcionarios reales, alto clero, secretarios, etc.), se va a producir una nivelación igualitaria de escalones sociales. En efecto, no se van a conocer las divisiones de clases de la metrópoli, sino que el criterio predominante va a ser la antigüedad: así, los emigrados a Indias se clasificaron en «primeros conquistadores», «segundos conquistadores», «primeros pobladores», etc. ${ }^{51}$.

El patrón social gira en torno a la figura del conquistador que, mediante su esfuerzo y riesgo personal, pretende conseguir fama, gloria y honra, es decir, reconocimiento público de sus méritos. Junto a éstos están los que a toda costa persiguen títulos, y a los que Baltasar Dorantes de Carranza se refiere en los siguientes términos:

«... aunque en los conquistadores hubo algunos hijosdalgo, ahora lo son por la presunción todos, porque toda hidalguía de su naturaleza y cosecha tubo sus principios de los hechos y servicio del rey [...]. Mas la gente que después fue viniendo y poblando el reino le ha lucido mucho, y entremetídose con los mesmos conquistadores por casamientos y parentescos, con que ya son todos casi uno» (op. cit., pág. 12).

«Otros que pasaron por grumetes o marineros, y en llegando a las Indias se llamaron don Fulano, como los que vienen de las casas y banco, que así lo quiero llamar, de Córdoba y Sevilla, embarcándose para esta tierra: so doña Angela, doña Alberta, etc., tomando ellos y ellas títulos y dones fingidos, con mil embustes». (Id., pág. 233).

Este deseo desmedido de títulos y cortesías, va a influir en la lengua de la incipiente sociedad criolla: «contra lo que se cree -señala A. Rosenblat- no se manifiesta una vulgarización del habla, sino todo lo contrario: el español se volvió más ceremonioso, más extremo en sus cortesías y en sus fórmulas de tratamiento ${ }^{52}$. Un ejemplo de ello, nos lo indica el Inca Garcilaso, quien cuenta cómo Piarro cuida el título que se le da a Pedro de Alvarado:

«... se dio más priesa en su viaje por recibirles en aquel hermoso valle y hospedar y regalar a don Pedro de Alvarado y hacerle la honra que un tan valeroso capitán merecía [...]. A don Pedro dio don Francisco todo su poder, y mandó a los suyos que absolutamente le llamasen el gobernador y que a don Diego de Almagro y a él los llamasen por sus nombres sin otro título» (pág. 104).

51 De hecho, así se estructura la Sumaria Relación... de B. Dorantes de Carranza (cfr. n. 29). Posteriormente, se producirá otra división social más fuerte si cabe: la que se establece entre los criollos, hijos de los conquistadores y pobladores, y los oriundos de España que llegaban a las Indias bajo la protección de virreyes y altos personajes. «La división entre estos dos sectores de la clase blanca dominante, perceptible en 1576, se había convertido en un verdadero abismo hacia 1600. Los «nuevos ricos» trataban a los descendientes de los conquistadores con insultante indiferencia...» I. Leonard, Los libros del conquistador (México: FCE, 1959), pág. 243.

52 Lengua literaria y lengua popular en América (Caracas: Universidad Central de Venezuela, 1969), pág. 9. 
Asimismo, de Gonzalo Pizarro cuenta:

«todos le hacían honra como a superior, acompañándole do quiera que iba, a pie o a caballo, y él se había con todos, así vecinos como soldados, tan afablemente y tan como hermano, que ninguno se quejaba de él. Nunca vi que nadie le besase la mano, ni él la daba, aunque se la pidiese por comedimiento. A todos quitaba la gorra llanamente y a nadie que lo mereciese dejó de hablar de vuesa merced». (pág. 309).

El uso del tratamiento honra a quien lo dice, y es muestra de liberalidad y nobleza, pero al que los escatima, le hace caer en boca de maldiciones y envidiosos, como le ocurrió al virrey Andrés Hurtado de Mendoza, a su llegada a Paita en $1556^{53}$.

De estos y otros testimonios, muy abundantes, que ofrecen los escritores de la época se puede deducir que, hacia mediados del s. XVI, vos es ofensivo con inferiores de calidad y, por supuesto, entre iguales, tal había sido la expansión social de este tratamiento. Dicha difusión debe estar relacionada con un cambio en la sociedad del XVI. En efecto, si la estratificación social está perfectamente clara y delimitada, también lo estará el uso de los tratamientos. La evolución y el «desorden» de éstos, hace pensar en un trasfondo de cambio social. De esto se hace eco M. Alemán:

«... vía escuderos, criados y a oficiales de obra usada, sacarlos de sus oficios para otros de todo punto repugnantes, como el calor del frío, y tan distantes a su calidad como el cielo de la tierra.

Llamástelos ayer con tu criado, no dándoles más que un vos muy seco, que apenas les cabía. Ya te envían hoy a llamar con un portero, y para tu negocio se lo suplicas, no cansándote de mercedes, pidiéndole que te las haga». (pág. 269)

Muchos otros testimonios, además de los anteriormente aludidos, encontramos en la obra de Quevedo, para quien el abuso de estos tratamientos fue objeto constante de su sátira ${ }^{54}$.

La influencia que en dicho cambio pudo tener la conquista y población del territorio americano, es algo que aún no se ha valorado en sus justos términos ${ }^{55}$. El cambio social se dio con mayor ímpetu al otro lado del océano, donde el anhelado medro personal del hombre renacentista puede hacerse realidad; si bien muchos fracasaron, otros volvieron con riqueza y honra, haciendo ostentación de cortesías que en la península, pese a todo, tenían un uso más restringido. Así le ocurrió al hermano de Santa Teresa, según el conocido testimonio de esta autora ${ }^{56}$. Por idéntico motivo, Juan Ruiz de Alarcón sufrió las críticas de Quevedo:

${ }^{53}$ Op. cit., págs. 136-137.

54 Cfr. op. cit., págs. 999, 688-689, 867-868.

5ș Cfr. Friederici, op. cit., págs. 435-436.

56 A. Rosenblat, art. cit., pág. 74. 
«¿Quién es gámbaro con don

y cohete con varilla?

Corcovilla».

(«Sátira contra don Juan de Alarcón», pág. 1188).

En conclusión, toda la documentación del siglo XVI manejada indica que la utilización de los tratamientos tuvo un proceso de difusión por todas las capas sociales a lo largo del siglo XVI, lo cual produjo un marcado desgaste en algunas de dichas formas hasta el punto de hacerles perder todo valor de respeto. Esto dio lugar a la aparición de nuevas cortesías, que a su vez entraron en el enorme engranaje de usos sociales.

Esta situación se produce de idéntica forma en el Nuevo Mundo, sólo que allí, como tantas otras cosas, cobró un mayor dinamismo en cuanto a su expansión, al tiempo que, dada la extensión del territorio, las modas lingüísticas de la metrópoli no llegaron a las zonas alejadas y mal comunicadas con las cortes virreinales, lo cual ha dado lugar a la conservación de ciertos usos arcaicos.

La centuria siguiente agotará las posibilidades de designación de estas formas, hasta que se llega a una cierta estabilidad basada en una doble posibilidad: tú / usted. 
